\title{
Comparative Tests of Voltage Suppressors for the Protection of Electronics against High-Altitude Electromagnetic Pulse (HEMP)
}

\author{
Vladimir Gurevich, Ph.D. \\ Central Electrical Laboratory Israel Electric Corp., Haifa, Israel \\ *Corresponding Author: Vladimir Gurevich, Central Electrical Laboratory Israel Electric Corp., Haifa, \\ Israel

\begin{abstract}
Today, the market offers many different voltage suppressor types, significantly varying in both specification and cost. Alongside with the shielding of the electronics cabinet and the cable, such elements appear to be one of the basic HEMP-protection measures. However, dozens of them must be installed inside every single cabinet to ensure the required protection. Thus, considering the hundred-fold difference in cost, the type of applied suppressors should be selected very carefully. Since the publications comparing the specifications and the effectiveness of different suppressors do not fully reflect the actual usage conditions, additional researches were necessary.
\end{abstract}

Keywords: voltage suppressor, varistor, TVS-diode, HEMP, electromagnetic pulse, electronic equipment

\section{INTRODUCTION}

Usually, the protection against powerful and dangerous impacts of lightning discharges and HEMPs is realized using the voltage suppressors. Gas discharges tubes (GDT), metal-oxide varistors (MOV), and TVS-diodes are the three basic types of such suppressors and are widely available on the market. All of them are widely used since they have a good track record of protecting against lightning discharges and switching surges. However, the situation is different when it comes to HEMP, since its standard E1 component of the HEMP is very short (2.5/25 nanoseconds) compared to the length of standard lightning discharge pulse 1.2/50 microseconds. Since HEMP is a thousand-fold shorter than lightning discharge, voltage suppressors designed for the HEMP protection should be especially fastacting. Experts consent that sometimes the GDT are not suitable for HEMP protection, due to their lower speed and spur increase in breakdown voltage with an increase in the rise time (i.e. leadingedge steepness) [1]. However, they are ambivalent about varistors and TVS-diodes. Many experts think that a regular varistor is too slow to ensure optimal protection against HEMP and a TVS-diode is the only option providing the required parameters. Actually, modern powerful TVS-diodes capable of passing pulse currents of $3 \mathrm{kA}, 6 \mathrm{kA}$, and $10 \mathrm{kA}$ outperform varistors of the same power in many parameters. Unfortunately, there is another much higher characteristic. TVS-diodes are more than 200 times expensive than varistors of the same power and voltage class. Concerning the selection of HEMP-protection measure, this difference in cost is a very significant issue, since dozens of voltage suppressors are required to protect a single standard electronics cabinet [1]. In this context, the question arises as to whether the difference in varistor and TVS-diode speed is that significant and if it warrants such a big difference in cost. Herewith, it should be noted that varistor and TVS-diode speed was always measured by different authors in the sterile laboratory environment under all specific characteristics of high-frequency circuits and their test methods. While such an approach is correct when we need to get the exact data on the speed of avaristor or TVS-diode, it is unlikely capable of giving their performance data under the actual operating conditions (inside the electric cabinets) since such conditions have little, if anything, to do with the laboratory environment, and actual circuits are not high-frequency at all. In reality, long wires and cables enter the cabinets from outside, while inside them, regular unshielded connector wires are packed in parallel in the plastic cable trays. Consequently, it is obvious that actual operating conditions of varistors and TVS-diodes have nothing in common with a laboratory test environment and the speed data received from the laboratory tests are hardly applicable to the actual operating conditions. Hence, I have investigated that problem [1], 
and the results received proved the possibility to use cheaper varistors as the basic means of HEMPprotection in real-world environments. However, low voltage apparatus and low amplitude pulses were applied within those studies and the studies were performed to test the low-voltage voltage suppressors.

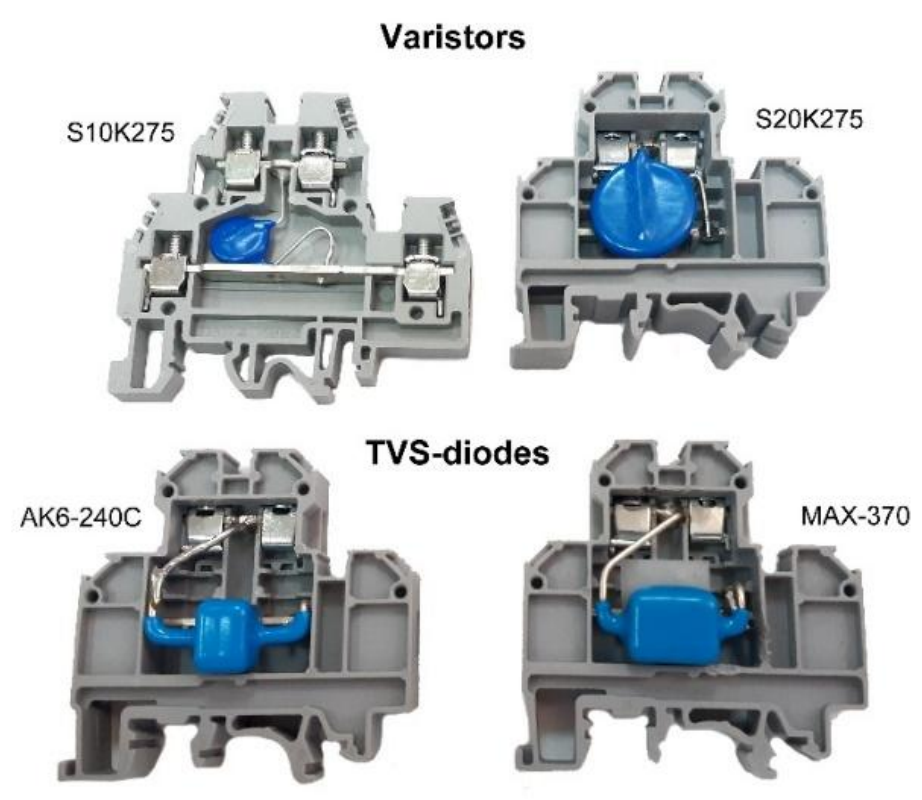

Figure1. Two varistor types (top) and two TVS-diode types (bottom) with similar specifications selected for tests.

\section{PURPose OF THE RESEARCH}

The purpose of this research is to compare the response of high-power varistors and TVS-diodes on the same high-voltage pulses with parameters similar to the real parameters of the HEMP, under conditions close to the real-world operation inside the electronics cabinets.

\section{Method, TeSt SubJeCT AND EQUiPMENT}

For tests, two varistor types and two TVS-diode types with similar specifications were mounted on standard DIN-rail terminal blocks, see Fig. 10.1. The specific configuration was selected as it can be easily realized inside the equipment cabinets.

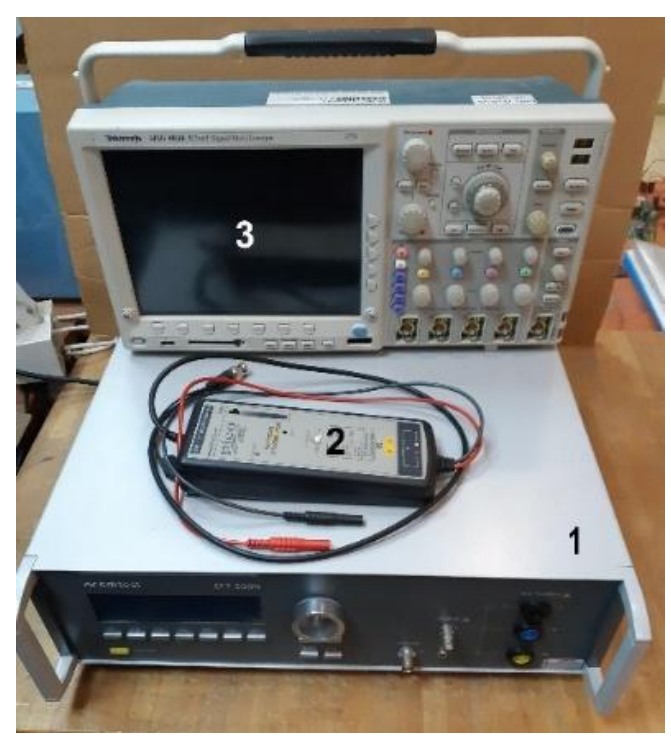

Figure2. Equipment used during the test. 1 - Generator of short high-voltage pulses (Electrical Fast Transient) EFT 500N (Emtest) with output voltage up to $7 \mathrm{kV}, 2$ - active differential high-voltage high-frequency voltage probe TA044 (Pico Technology), 3-oscillograph MSO 4034 (Tektronix). 


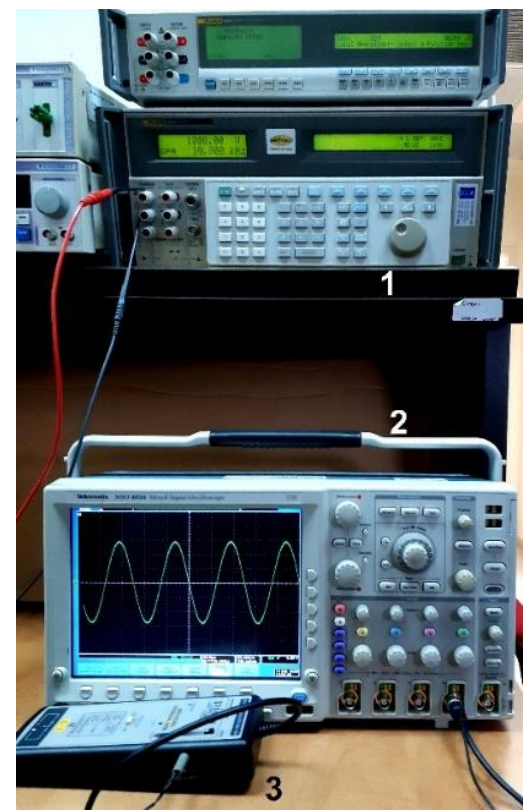

Figure3.Calibration of the active differential high voltage probe (3) for oscillograph (2) using calibrator FLUKE 5520A (1).

The corresponding equipment was used during the tests, see Fig. 10.2.

Before the test, the voltage probe TA044 was calibrated using the high-class calibrator type FLUKE $5520 \mathrm{~A}$ under the sine voltage up to $1000 \mathrm{~V}$ and $10 \mathrm{kHz}$, see Fig. 10.3.

The Generator EFT $500 \mathrm{~N}$ with an output voltage up to $7 \mathrm{kV}$ is designed for testing equipment immunity to Electrical Fast Transient of standard shape [2]. Upon Fourier transform, this non-sine complex waveform will certainly produce a big range of harmonics (i.e. set of sine waveforms with different frequencies and amplitudes). This is a problem since active differential voltage probes have non-ideal frequency response functions (FRF) within the required frequency range $(0.1 \mathrm{MHz}-$ 100MHz), see Fig. 10.4.
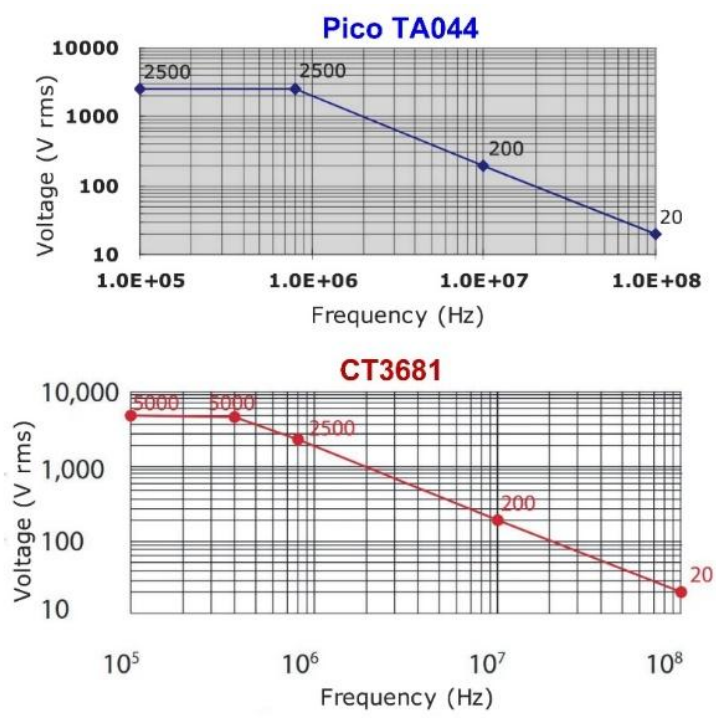

Figure4.Typical FRFs of active differential high-voltage voltage probes (e.g. type Pico TA044 and CT3681) for oscillograph.

Thus, the attenuation rates of different harmonics of the test pulse generator output signal will significantly differ from each other inside such a divider. As a result, the non-sine complex waveform coming out of the probe to the oscillograph will be significantly distorted: its form will be too different from the real form of this pulse. Additionally, inductance and capacitance of wiring and probe outputs will start the oscillatory process, see Fig. 10.5. 


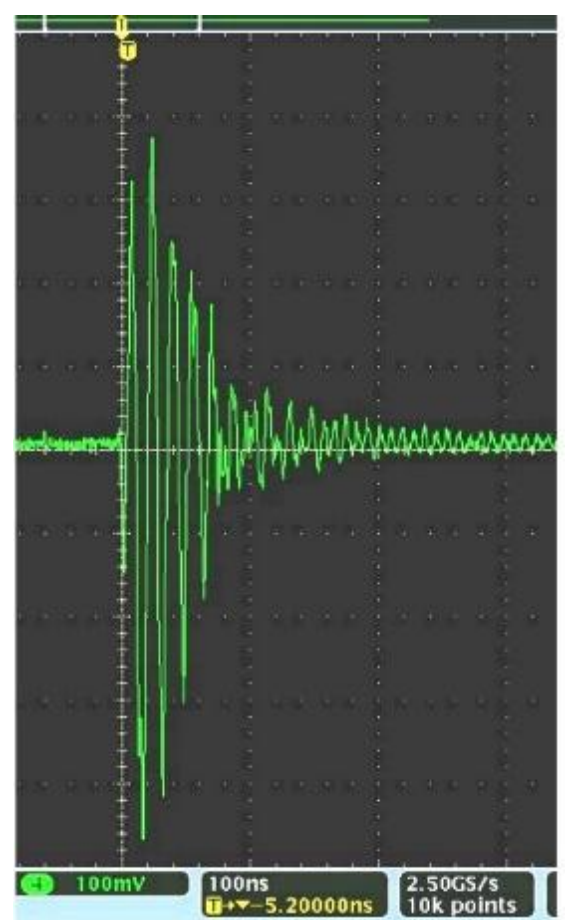

Figure5. The appearance of the generator test pulse passed through the active differential voltage probe on the oscillograph screen.

Since the purpose of the research was only to compare varistor and TVS-diode response under the same operating conditions, and exact measuring of time of response on the standard pulse was not the task, in my opinion, the application of such a distorted pulse (on the oscillograph screen, not in reality) was acceptable.

\section{TEST RESUlts}

At first, I performed comparative tests of two different varistor types and two different TVS-diode types, see Fig. 10.6.

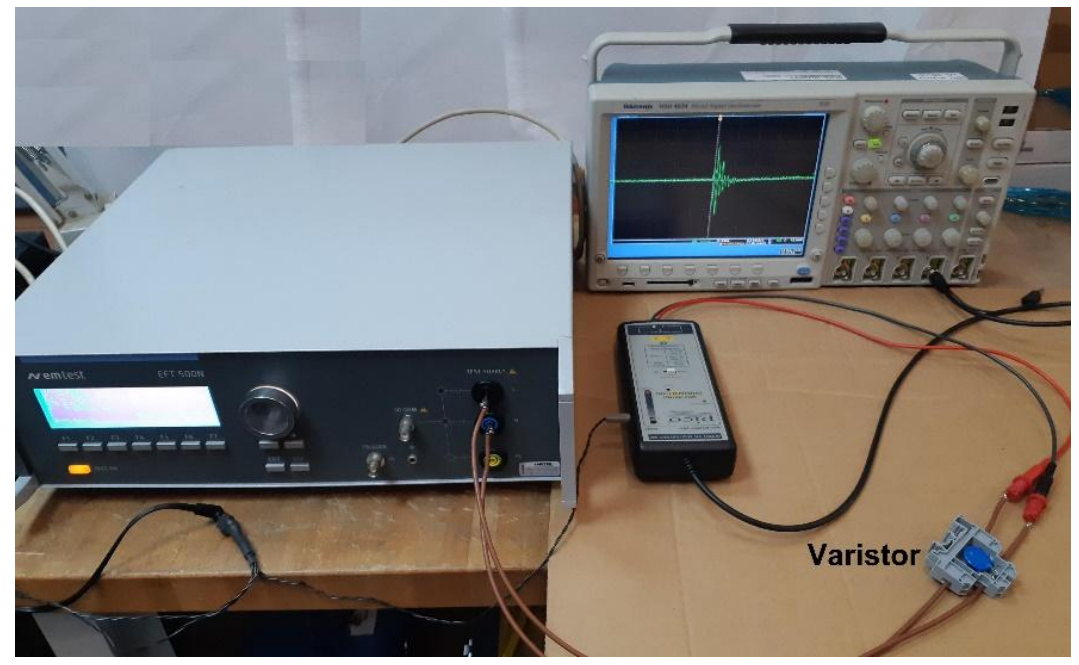

Figure6. Test of varistors

Since the test results, see Fig. 10.7, showed that there was no essential difference between the two varistor types and two TVS-diode types in terms of response on the test pulse, only one varistor type and one TVS-diode type were used for the further tests. The same tests were performed to define the impact of the length $(0.5 \mathrm{~m}$ and $2.0 \mathrm{~m})$ of wiring connecting the test pulse generator with the varistor and TVS-diode. Those tests also showed no significant impact of the wire length on the residual voltage that appeared on the TVS-diodes or varistors. Thus, a wire length of $0.5 \mathrm{~m}$ was used in further tests.

International Journal of Research Studies in Electrical and Electronics Engineering (IJRSEEE) Page | 29 
The test of the TVS-diode and varistor impact on the test pulse, see Fig. 10.8, showed that both suppressors reduced pulse amplitude and accelerated its attenuation, and the performance of the S20K275 varistor was as good as of the AK6-240C TVS-diode.
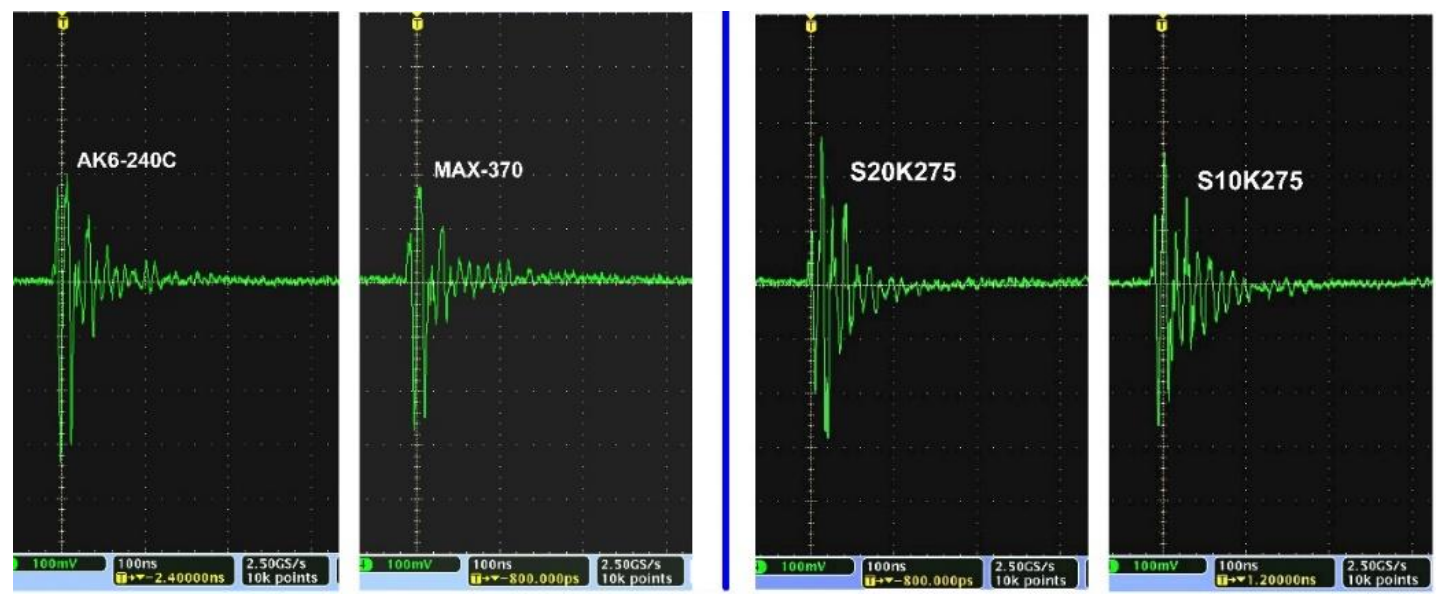

Figure7. Oscillograph charts of residual voltage on two different types of TVS-diodes (left) and varistors (right).
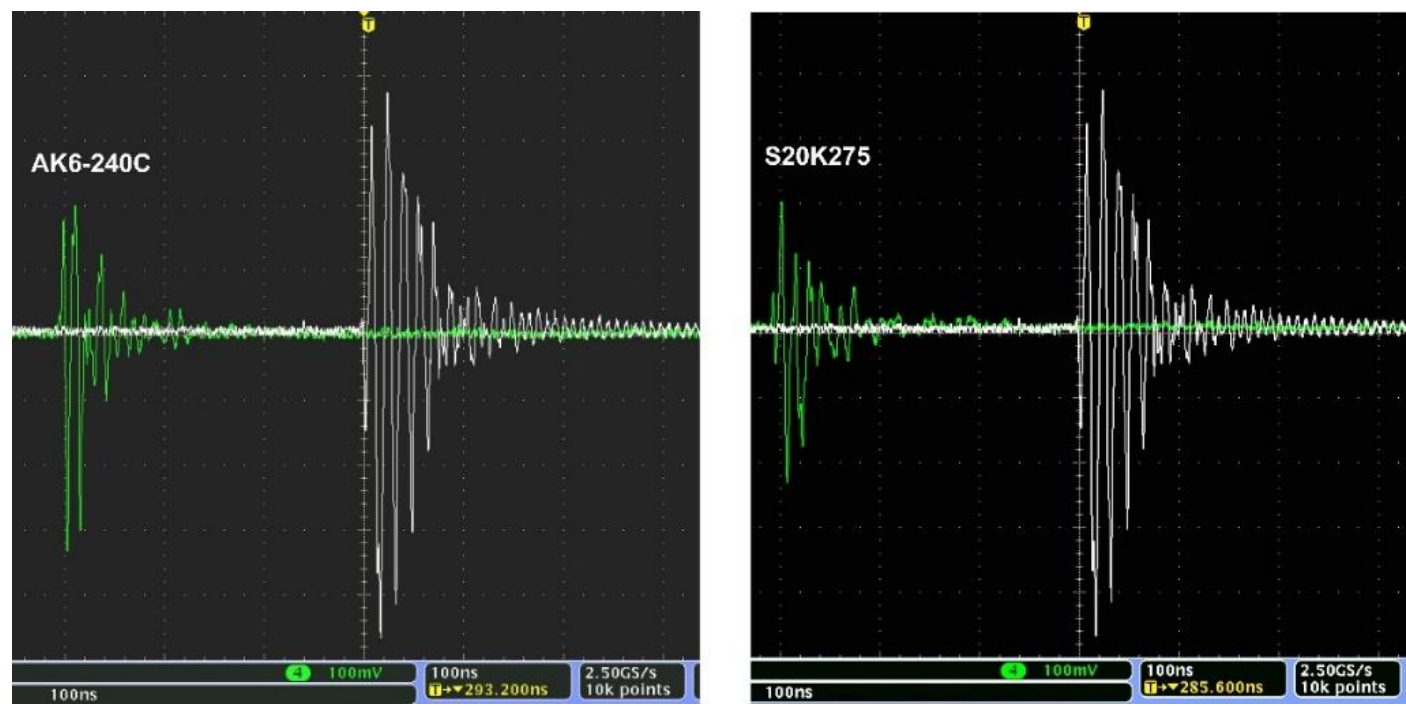

Figure8. The residual voltage on the S20K275 varistor and the AK6-240C TVS-diode under the same test pulse from the generator (right on both oscillograph charts).

At this point, the original purpose of the test was reached as the test proved that under the realistic conditions, the varistor is as good as the TVS-diode when it comes to HEMP-protection effectiveness. However, the tests were continued to define the capability of different additional elements combined with the varistor to further attenuate the test signal. For example, the additional choke inserted into the protected circuit before the varistor is considered as a measure to improve the varistor performance. Some companies produce such chokes in plastic enclosures to be installed on a DIN-rail and combined with varistors (e.g., chokes DSH type, produced by CITEL).

While such a solution is commonly perceived as effective, I made a test (see Fig. 10.9) with a choke type EEK55246-221M-50A designed specifically for electromagnetic interference suppression. The choke was inserted into the wire connecting the test pulse generator and varistor. The test result was unexpected (see Fig. 10.9).

Due to such a strange result, I additionally measured the FRF on this choke, see Fig. 10.10. That measurement showed that within the HEMP frequency range $(0.1 \mathrm{MHz}-100 \mathrm{MHz})$, that choke was not effective (probably due to the high own internal capacitance of that choke due to the helical type winding). 

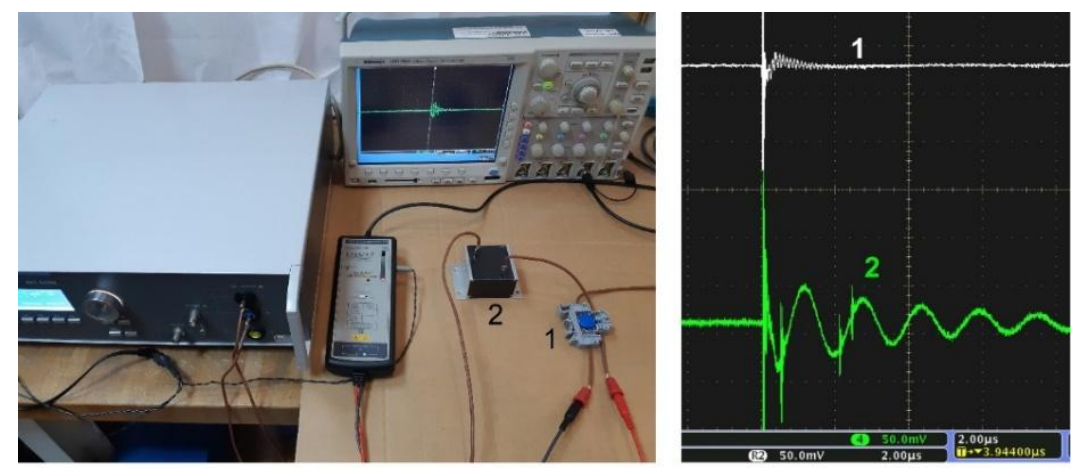

Figure9. Test of varistor performance: varistor (1), choke (2) connected before the varistor and the resulted oscillograph chart showing residual voltage on the varistor (1), and on the same varistor with a preceding choke (2).

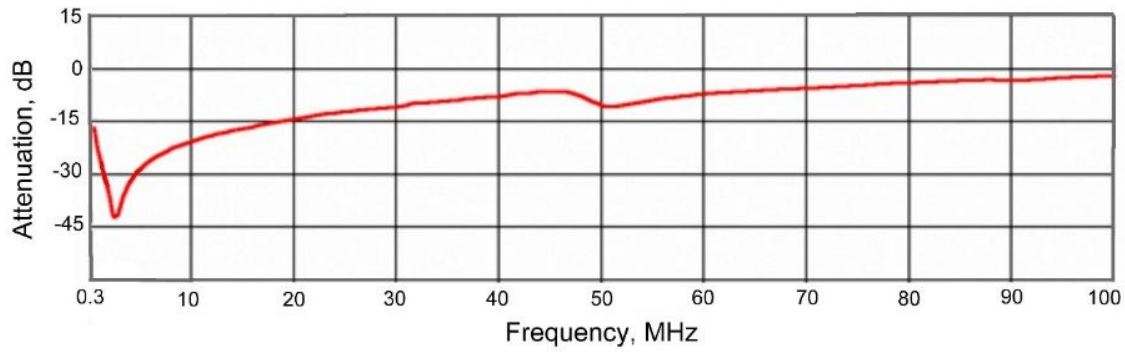

Figure10. Frequency response functions of choke type EEK55246-221M-50A with helical type winding

Such an inverse effect (significant increase in residual voltage amplitude and oscillation duration instead of their decrease, see Fig. 10.9) of choke and varistor combination is possibly attributable to resonance appearing in the oscillation circuit formed by the capacitances of choke, varistor, and wiringwith choke inductance. It is obvious, that under the high frequencies this result applies to the particular test conditions only, and will differ upon the different conditions. However, this possibility itself should be considered as a red flag, since under the real operating conditions, the high-frequency characteristics of the cabinets can be very different and thus unpredictable. In other words, this phenomenon, when negative HEMP impact on electronics enclosed in a cabinet spurts instead of decreases, is possible in the real-world environment. This means that considering the relatively low attenuation introduced by such a choke (while it was selected specifically based on the required specification) it should not be used as a means of a secondary HEMP-protection.
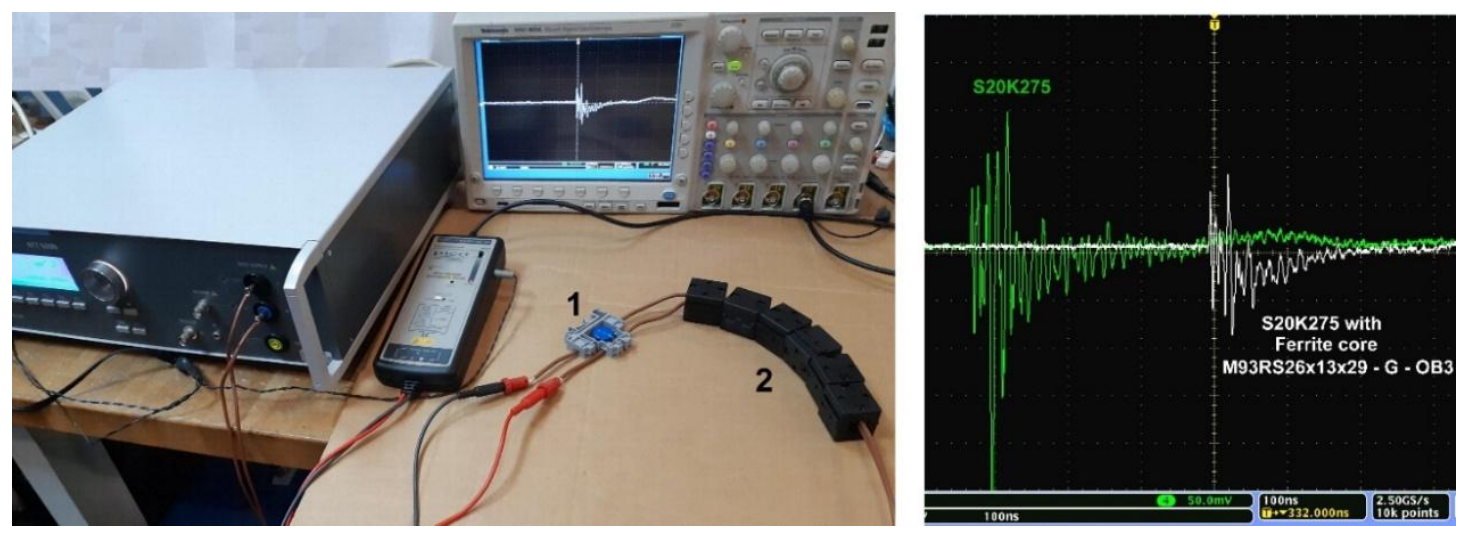

Figure11.Test of performance of varistor type S20K275 (1) with the set of 6 ferrite cores in plastic conduit type M93RS26x13×29-G-OB3 (2) mounted on wires before the varistor.

Unlike the in-line choke, the ferrite cores designed as half-rings to be mounted on the connecting wires before the varistor provide an absolutely different result, see Fig. 10.11. For comparison, as can be seen on an oscillograph chart of residual voltages on an individual varistor (left), and on the same varistor with ferrite cores installed (right). As can be seen on the graphs, the ferrite filter suppresses both amplitude and length of the pulse improving the varistor performance.

International Journal of Research Studies in Electrical and Electronics Engineering (IJRSEEE) Page | 31 
The varistor and LC-filter combination appeared to be equally effective. This change in the connection diagram was required because such filters were not designed for direct input of high voltage and need a preceding pulse voltage suppressor, see Fig. 10.12.

For comparison, the graphs of the generator test pulse (right) and the residual voltage on the varistor with the LC-filter (left) are presented.
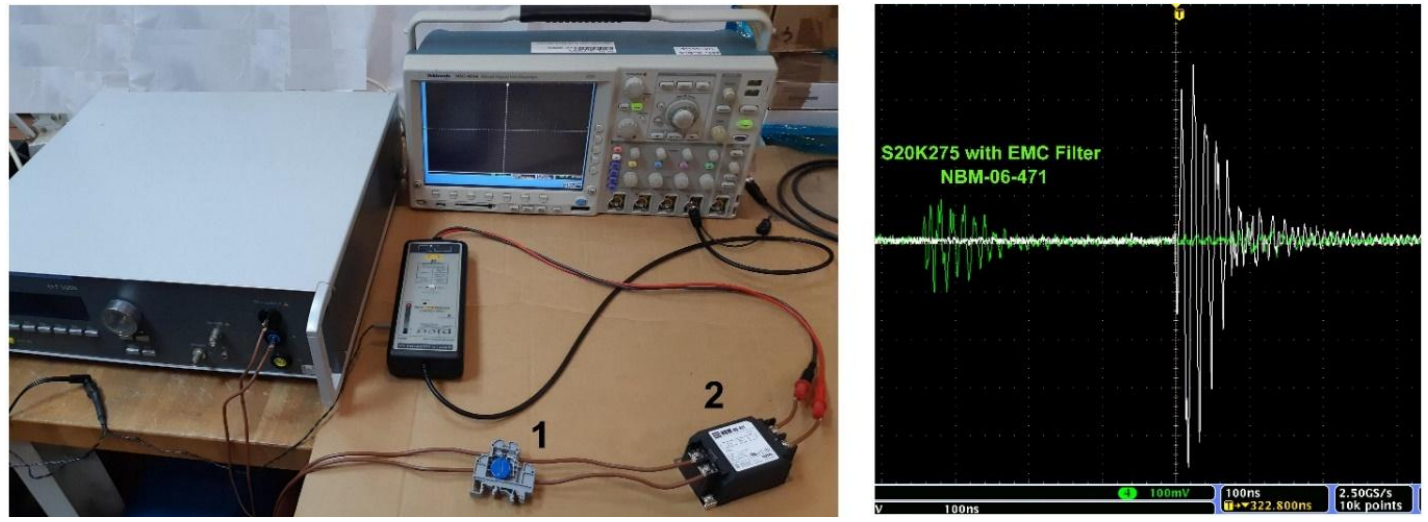

Figure12. Test of performance of varistor type S20K275 (1) with LC-filter type NMB-06-471 (2) inserted in circuit after the varistor.

\section{CONCLUSIONS}

1. Inexpensive varistors used for basic HEMP-protection of electronics installed in control cabinets can be no less effective than expensive TVS-diodes.

2. The combined use of varistors and LC type or ferrite filters can significantly improve the effectiveness of protection.

3. However, varistors should not be combined with chokes connected in series with wires entering the electronics cabinets.

\section{REFERENCES}

[1] Gurevich V. Protecting Electrical Equipment: Good Practices for Preventing High Altitude Electromagnetic Pulse Impacts. - De Gruyter, Berlin, 2019. - 386 p.

[2] IEC 61000-4-4 Electromagnetic compatibility (EMC) - Part 4-4: Testing and measurement techniques Electrical fast transient/burst immunity test, 2012.

Citation: Vladimir Gurevich, (2020)"Comparative Tests of Voltage Suppressors for the Protection of Electronics against High-Altitude Electromagnetic Pulse (HEMP)", International Journal of Modern Studies in Mechanical Engineering, 6(2), pp. 26-32. DOI: http://doi.org/10.20431/2454-9711.0602004

Copyright: () 2020 Authors, This is an open-access article distributed under the terms of the Creative Commons Attribution License, which permits unrestricted use, distribution, and reproduction in any medium, provided the original author and source are credited. 